\title{
TRATADO COISLINIANO
}

\section{Apresentação}

O Tratado Coisliniano está na segunda parte do manuscrito n.120 da coleção Coislin da Bibliothèque Nationale de Paris, de onde provém seu nome. A redação deste manuscrito é assinalada por Devreesse (Janko, 1984) e outras autoridades como datando do início do séc X, mas a análise dos extratos, sumários e comentários aristotélicos nele compreendidos fazem crer que o seu conteúdo remonta ao séc. VI, pois reflete o ensino filosófico da época, sobretudo nas partes comentando o Isagoge de Porfírio, que ocupam a maioria das páginas do códice. O Tratado Coisliniano ocupa as folhas 248v, 249r e 249v do manuscrito, não possui título nem autoria. É provavelmente um epítome dos conteúdos do Livro II da Poética de Aristóteles, mas pode ter sofrido influências dos ensinamentos retóricos posteriores ao Liceu (porém, como a influência é recíproca, não há como distinguir a proveniência com exatidão). Segundo Cooper (1922):

Talvez possamos assegurar que o Tratado mostra diferentes estratos de criação em seu desenvolvimento até o estado atual, que revela a mão, primeiro de um estudante industrioso e fiel a Aristóteles, e depois de um imitador menos inteligente, que deseja a todo custo pôr sua obra à altura da doutrina e dos termos da Poética, e que a definição de comedia parece merecer a censura infligida por Bernays e Bywater.

Para esta tradução, servi-me principalmente dos materiais contidos no estudo de Richard Janko, Aristotle On Comedy, Towards a reconstruction of Poetics II; o texto por ele estabelecido, sua tradução e, sobretudo, as pranchas com reproduções fotográficas das três páginas do manuscrito. Também me foi útil a edição de J. Vahlen de 1885, reeditada em 1964, que se atém mais estritamente a edição do manuscrito, sem a quantidade de correções de Janko, e fiel à disposição gráfica do mesmo. Minha tradução aproxima-se mais do texto grego deste último, sendo bastante diferente da edição feita por Janko, por dois motivos principais: primeiro, meu objetivo, diferente do dele, não é reconstruir aqui o texto original de Aristóteles, de modo que me eximi da quantidade de correções e adendos que Janko faz, usando manuscritos adjacentes (sobretudo os Prolegômenos dos manuscritos das obras de Aristófanes, editados por Koster [Janko, 1984]) - minha tradução visa tão só o manuscrito do Tratado; segundo, a consulta às pranchas dos manuscritos permitiu- 
me algumas construções diferentes, sobretudo na hora de interpretar em sintaxe dissertativa os freqüentes diagramas visuais. Fora esses dois motivos, as distâncias decorrem apenas das razões de sempre: línguas e compreensões diferentes.

Apesar de visar tão somente à tradução do Manuscrito, aceitei, para a compreensibilidade do texto, algumas poucas correções e adendos propostos pelo estabelecimento de Janko e outros, os quais estão devidamente assinalados em notas de rodapé. Tomei a liberdade também de acrescentar subtítulos às divisões propostas por Janko.

\section{Tradução}

Conspectum siglorum:

[ ] delenda

$<>$ inserenda

( ) translatio ins.

\section{$<$ I e II. Gêneros Literários>}

Da produção literária, uma parte é não mimética, outra parte é mimética.

A literatura não mimética reparte-se em investigativa e educativa, e esta(s) ${ }^{1}$ em didática e especulativa.

Já a literatura mimética reparte-se, de um lado, em narrativa, de outro, em dramática, i.e. que se exprime por ações, a qual se divide ainda em comédia, tragédia, mímica e sátira.

\section{<III. Catharsis $>$}

A Tragédia afasta as afecções da alma relativas ao medo por meio de compaixão e terror, e [que $]^{2}$ almeja estabelecer uma proporção do medo; tem como mãe a dor.

1 No manuscrito a divisão aparece em forma de diagrama: a subdivisão em "didática" e "especulativa" vem abaixo da divisão em "investigativa" e "educativa"; Bergk liga a subdivisão apenas ao gênero educativo (Janko, 1984). Vahlen mantém a diagramação do manuscrito. Como Janko, adaptamos o diagrama para uma forma discursiva, mas sem as suas correções.

2 Kà̀ ŏ $\tau \imath$ excerptoris vestigium 


\section{<IV. Definição da Comédia >}

Comédia é uma imitação de uma ação risível e desprovida de grandeza ${ }^{3}$, acabada, separada em cada uma das partes no tocante aos formatos; representada por atores e também $\mathrm{m}^{4}$ por meio de narrativa, consumando pelo prazer e pelo riso a purgação de tais afecções; tem como mãe o riso.

\section{$<$ V. Causas do Riso $>$}

Mas o riso é gerado - seja pelas falas - seja pelas ações.

1) Por homonímia

2) $<$ Por $>$ sinonímia

3) $<$ Por $>$ prolixidade

4) $<$ Por $>$ paronímia -

4a) de prótese e aférese

4b) $<$ de $>$ diminutivo.

4c) $<$ de $>$ trocadilho - com voz, - e com coisas de gênero semelhante.

5) $<$ Pela $>$ forma de falar ${ }^{5}$

\section{$<$ VI. Riso proveniente de ações $>$}

O riso (surge) a partir das ações:

1) Desde a assimilação, que se usa para o pior ou melhor

2) Desde o engano

3) Desde o impossível

4) Desde o possível e incoerente

5) Desde a quebra de expectativa

3 No sentido de nobreza.

4 Kaibel acrescenta a negação < o U > (CGF) (Janko, 1984).

5 Cf. Poética 19, 1456b 8-13. 
6) Desde a caracterização chula das personagens

7) Desde o uso de danças grosseiras

8) Quando alguém, tendo a possibilidade, deixa de lado o que é melhor e toma para si o que é pior

9) Quando o discurso é desarticulado na medida em que também não tem coerência alguma.

$<$ VII. Ênfase $>$

A comédia difere da injuria, porque, de um lado, a injuria expõe abertamente os defeitos salientes, enquanto aquela precisa da chamada "ênfase".

$<$ VIII. Bufão $>$

O bufão busca escarnecer ${ }^{7}$ das falhas da alma e do corpo.

\section{$<$ IX. Simetria $>$}

Deve haver uma proporção do terror nas tragédias e do riso nas comédias.

\section{$<X$. Aspectos da Comédia $>$}

Aspectos da comédia: enredo, caráter (das personagens), pensamento, elocução, canto, espetáculo.

6 No sentido original de "sugestão significativa", i.e., como figura da elocutio. À medida que esta figura, para ser efetivamente significativa, muitas vezes demandava do ator uma força expressiva maior, este aspecto da pronuntiatio tendeu nas línguas modernas a resignificar a "ênfase" no domínio da elocutio. Cf. Lausberg, Elemente der Literarischen Rhetorik, §209.

$7 \dot{\varepsilon} \lambda \dot{\varepsilon} \gamma \chi \varepsilon \imath \nu$ originalmente quer dizer: envergonhar, donde também: censurar e, posteriormente, nas disputas dialéticas: refutar. 
$<$ XI. Enredo $>$

Enredo cômico é aquele que tem sua construção com ações em torno do risível.

$<$ XII. Personagens $>$

Personagens característicos da comédia: os iconoclastas e também os irônicos e os fanfarrões.

\section{$<$ XIII. Pensamento $>$}

Há duas partes do pensamento: opinião e prova. $<$ Há cinco provas $>^{8}$ : juras, pactos, testemunhos, confissões, leis.

\section{<XIV. Elocução >}

Elocução cômica é comum e vulgar.

O poeta cômico deve atribuir às personagens a língua pátria das mesmas, mas na língua local dele.

\section{$<X V$. Canto \& Espetáculo $>$}

O canto é uma particularidade da música, desde a qual deverá receber as bases independentes.

O espetáculo, com grande utilidade para as atuações dramáticas, sustenta a harmonia.

\section{$<$ XVI. Aspectos $>$}

O enredo e a elocução e o canto são observados em todas as comédias, mas pensamentos e caráter e espetáculo em $<$ não $>{ }^{9}$ poucas.

8 Ins. Kaibel (CGF) (Janko, 1984).

9 Ins. Janko, conforme Poética 6, 1450a 12 


\section{$<$ XVII. Partes da comédia $>$}

Há quatro partes da comédia: prólogo, intervenção coral, episódio e êxodo.

1) Prólogo é uma parte da comédia que vai até a entrada do coro.

2) Intervenção coral é o canto cantado pelo coro, quando tem tamanho suficiente.

3) Episódio é o que fica entre dois cantos corais.

4) Êxodo é o que é falado no fim pelo coro.

\section{$<$ XVIII. Fases da comédia $>$}

Da comédia:

1) Antiga: que se excede no risível;

2) Nova: que o dispensa e inclina-se para o sério;

3) Média: que é uma mistura de ambas.

\section{REFERÊNCIAS BibLIOGRÁfiCAS}

Aristóteles. Opera, Berlin, Academia Regia Borussicae, 1831 (Ed. I. Bekker, reed. O. Gigon, Bruxelles, W. De Gruyter, 1960-87) . De Arte Poetica Liber. Oxford: Clarendonian press, 1965, 1982 (Ed. Kassel) . De Arte Poetica Líber. ed. 3, Leipzig 1885 (ed. 1 = 1867, ed. 2 = 1874), Hildesheim, 1964 (Ed. Vahlen) . Poética. São Paulo: Abril Cultural, 1973 (Ed. E. Souza) . On Comedy, London, Duckworth, 1984 (Ed. R. Janko) . Poética de Aristóteles. Ed. trilíngüe. Madrid: Gredos, 1974 (Ed.Yebra, V.G.) . La Poétique. [texto, tr., com.] Paris 1980 (Ed. Dupont-Roc, R.; Lallot, J.) . Ars Rhetorica. Oxford: Clarendonian press, 1989 (Ed. Ross) . Retórica. Lisboa, INCM, 1998 (Ed. M. A Junior, P.F.Alberto, A.N. Pena) 
. Fragmenta Selecta. Oxford: Clarendonian press, 1979 (Ed. Ross)

. History of Animals (books I-III). Londres: Harvard Universitry Press, 1993 (Ed. Peck) . Política. Lisboa, Vega, 1998 (Ed. A.C. Amaral \& C.C.Gomes)

Bernays, J. Zwei Abhandlungen über die aristolische Theorie des Drama: I. Grundzüge der verlorenen Abhandlung des Aristoteles über Wirkung der Tragödie; II. Ergänzung zu Aristoteles' Poetik, Berlin 1880 (Parte I pub. em Breslau 1857), Reed: Darmstadt 1968, trad. Ingl. Aristotle on the effect of tragedy, Articles on Aristotle 4: Psychology and Aesthetics ed. J. Barnes, M. Schofield, R. Sorabji.

Bonitz, Hermann, Aristotelis Opera, Immanuelis Bekkeri, Acad. Regia Borussica, reed. O. Gigon, Bruxelles, W. De Gruyter, 1961, Vol. V. Index Aristotelicus

Cooper, Lane An Aristotelian Theory of Comedy, with an adaptation of the Poetics and a translation of the Tractatus Coislinianus, Oxford 1922 [disponível em: http:/ /www.ucm.es/info/per3/cic/Numero7/1Tractatus.pdf ]

Janko, R., Aristotle On Comedy, towards a reconstruction of Poetics II, London, Duckworth, 1984

Lausberg, H., Elemente der Literarischen Rhetorik, München , Max Hueber Verlag, 1967 [Ed.R. Fernandes, Lisboa, F.C.G., 1993]

FERNANDO SANTORO

Faculdade de Filosofia Universidade Federal do Rio de Janeiro 